\title{
Situação epidemiológica da infecção por Toxoplasma gondii em equídeos na microrregião do Brejo Paraibano ${ }^{1}$
}

\author{
Ruy B. Oliveira Filho², Karla C. Malta ${ }^{3}$, Júnior M.B. Oliveira4, Pedro P.F. Albuquerque ${ }^{5}$, \\ Rinaldo A. Mota ${ }^{5}$, Vania L. Assis Santana ${ }^{6}$, Leucio C. Alves ${ }^{7}$ e José W. Pinheiro Júnior ${ }^{4 *}$
}

\begin{abstract}
Oliveira Filho R.B., Malta K.C., Oliveira J.M.B., Albuquerque P.P.F., Mota R.A., Assis Santana V.L., Alves L.C. \& Pinheiro Jr J.W. 2012. [Epidemiological situation of Toxoplasma gondii infection in equids from Brejo Paraibano microregion, Brazil.] Situação epidemiológica da infecção por Toxoplasma gondii em equídeos na microrregião do Brejo Paraibano. Pesquisa Veterinária Brasileira 32(10):995-1000. Laboratório de Doenças Infecto Contagiosas, Unidade Acadêmica de Garanhuns, Universidade Federal Rural de Pernambuco, Av. Bom Pastor s/n, Boa Vista, Garanhuns, PE 55296-901. E-mail: jrwilton@uag.ufrpe.br

The objective of the study was to characterize the epidemiological situation of Toxoplasma gondii infection in equids from Brejo Paraibano microregion, Northeastern Brazil. Antibodies against T. gondii were investigated in samples of 257 equids (204 horses, 46 mules and seven donkeys) in 26 properties. For serological diagnosis was used the Indirect Fluorescent Antibody Test (IFAT) and a cut-off of 1:64. The number of foci was found to be $46.1 \%$. In the samples analyzed, the overall prevalence was $7.8 \%$ (C.I. 4.8-8.8). The prevalence was $8.3 \%$ (C.I. $4.9-13.0$ ) for horses, $2.2 \%$ (C.I. $0.1-11.5$ ) for mules and $28.6 \%$ (C.I. 3.771.0) among donkeys. Logistic regression of the variables showed that the water source was a risk factor, because in those properties that supplied running water to the animals the risk of infection was 4.4 times higher than in those properties which provided standing water (OR 4.4; C.I. 1.0-19.0). This is the first report of the presence of antibodies against $T$. gondii in equids in this micro-region of Paraiba State. To reduce the risk of infection in these species, good quality water should be given to the animals, as well as access of cats to water sources and facilities where animals are kept must be avoided.
\end{abstract}

INDEX TERMS: Risk factors, equids, serology, Toxoplasma gondii, toxoplasmosis.

\footnotetext{
${ }^{1}$ Recebido em 31 de maio de 2012.

Aceito para publicação em 30 de junho de 2012.

${ }^{2}$ Discente do Programa de Pós-graduação em Ciência Animal Tropical, Universidade Federal Rural de Pernambuco (UFRPE), Campus de Dois Irmãos, Rua Dom Manoel de Medeiros s/n, Dois Irmãos, Recife, PE 52171900, Brasil.

${ }^{3}$ Discente do Programa de Pós-Graduação em Ciência Animal, Universidade Federal da Paraíba (UFPB), Campus II, Centro de Ciências Agrárias, Cidade Universitária, Areia, PB 58397-000, Brasil.

${ }^{4}$ Laboratório de Doenças Infecto Contagiosas, Unidade Acadêmica de Garanhuns, UFRPE, Avenida Bom Pastor, s/n, Boa Vista, Garanhuns, PE 55296-901, Brasil. *Autor para correspondência: jrwilton@uag.ufrpe.br

${ }^{5}$ Laboratório de Doenças Infecto Contagiosas/DMV, UFRPE, Campus de Dois Irmãos, Recife, PE.

${ }^{6}$ Setor de Bacteriologia, Laboratório Nacional Agropecuário em Pernambuco, Ministério da Agricultura, Pecuária e Abastecimento (MAPA/ Lanagro-PE), Rua Dom Manoel de Medeiros s/n, Dois Irmãos, Campus da UFRPE, Recife, PE 52171-030.

${ }^{7}$ Laboratório de Doenças Parasitárias dos Animais Domésticos, Departamento de Medicina Veterinária, UFRPE, Campus de Dois Irmãos, Recife, PE.
}

RESUMO.- Objetivou-se com o estudo caracterizar a situação epidemiológica da infecção por Toxoplasma gondii em equídeos na microrregião do Brejo Paraibano, região Nordeste do Brasil. Anticorpos contra T. gondii foram pesquisados em 257 amostras de equídeos (204 equinos, 46 muares e sete asininos) em 26 propriedades. Para o diagnóstico sorológico utilizou-se a Reação de Imunofluorescência Indireta (RIFI) e um ponto de corte de 1:64. 0 número de focos encontrado foi de $46,1 \%$. Nas amostras analisadas, a prevalência geral foi de 7,8\% (I.C. 4,8-8,8). A prevalência foi de $8,3 \%$ (I.C. $4,9-13,0$ ) para os equinos, $2,2 \%$ (I.C. $0,1-11,5$ ) para os muares e $28,6 \%$ (I.C. 3,7-71,0) entre os asininos. Na regressão logística das variáveis observou-se que a fonte de água foi um fator de risco, pois naquelas propriedades que forneciam água corrente para os animais o risco de infecção foi 4,4 vezes maior do que naquelas propriedades que forneciam água parada (OR 4,4; I.C. 1,0-19,0). Este é o primeiro relato da presença de anticorpos contra T. gondii em equídeos nessa microrregião do estado da Paraíba. Para 
diminuir os riscos de infecção nestas espécies, deve-se fornecer aos animais uma água de boa qualidade, bem como evitar acesso de gatos a fontes de água e instalações onde os animais são mantidos.

TERMOS DE INDEXAÇÃO: Fatores de risco, equídeos, sorologia, Toxoplasma gondii, toxoplasmose.

\section{INTRODUÇÃO}

Toxoplasma gondii é um protozoário intracelular obrigatório que infecta a maioria das espécies de animais de sangue quente, incluindo as aves e o homem, na maior parte do mundo (Fraser 1996). A toxoplasmose é uma doença importante pelos danos reprodutivos em várias espécies de animais e principalmente nos humanos (Fialho et al. 2009).

Coccídeos em geral têm ciclos de vida complexos. Embora a maioria seja hospedeiro-específico, e apenas transmitido por um ciclo fecal-oral, T. gondii também pode ser transmitido por via transplacentária, e por carnivorismo. Há três estágios infecciosos de T. gondii para todos os hospedeiros: taquizoítos, bradizoítos e esporozoítos (Dubey 2004).

Exames sorológicos para detecção de anticorpos anti- $T$. gondii em equídeos foram realizados em vários países. Nos Estados Unidos foi relatada uma soroprevalência de 6,9\% (Dubey et al. 1999a) e 0,4\% (Dubey et al. 2003); mas dados de países latino americanos mostram que anticorpos para T. gondii são frequentes (Argentina, 13,1\% e Costa Rica, 34,0\%) (Dubey et al. 1999b, Dangoudoubiyam et al. 2011). $\mathrm{Na}$ Turquia, Akca et al. (2004) e Karatepe et al. (2010) relataram uma soropositividade em equinos de $20,6 \%$ na província de Kars, e na província de Nigde soropositividade de 7,2\%, respectivamente. Anticorpos contra T. gondii também foram detectados em equinos na República Tcheca (Bártová et al. 2010). Shaapan et al. (2012) realizaram exames de 240 amostras de soro de cavalos de esporte no Cairo, Egito, utilizando Reação em Cadeia de Polimerase (PCR), Teste de Aglutinação em Látex (LAT), ELISA e Aglutinação Direta Modificada (MAT), que revelaram 53,8\%, 52,1\%, $50,8 \%$ e $39,2 \%$ de animais positivos, respectivamente. Soropositividade em equinos de $2,6 \%$ utilizando a Reação de Imunofluorescência Indireta (RIFI) e de aproximadamente $1 \%$ utilizando imunoblot foram obtidas na Coréia do Sul (Gupta et al. 2002). Balkaya et al. (2011) detectaram 62,0\% de soropositividade em asininos procedentes da província de Erzurum, na Turquia. No Brasil os dados existentes em equídeos, revelam prevalências variando de $1,5 \%$ a 32,8\% (Laranjeira, Ishizuka \& Hyakutake 1985, Gazêta et al. 1997, Vidotto et al. 1997, Garcia et al. 1999, Mendonça et al. 2001, Naves et al. 2005, Locatelli-Dittrich et al. 2006, Langoni et al. 2007, Camossi, Silva \& Langoni 2010, Coiro, Langoni \& Silva 2012).

Em equinos, este parasito está associado com quadros de encefalomielite (Boughattas et al. 2011). Beech \& Dodd (1974) relataram uma doença neurológica em equinos associada a organismos semelhantes ao Toxoplasma. No entanto, a infecção por T. gondii em equinos geralmente é inaparente, sendo caracterizada pela manutenção de títulos de anticorpos e presença de cistos teciduais (Langoni et al. 2007), progredindo subclinicamente e, portanto, o diagnóstico baseia-se principalmente no emprego de métodos sorológicos para detectar os anticorpos (Akca et al. 2004, Alanazi \& Alyousif 2011).

Em função de o Brasil apresentar o maior rebanho de equinos na América Latina e da importância da toxoplasmose para a saúde pública, objetivou-se com esse estudo caracterizar a situação epidemiológica da infecção pelo $T$. gondii em equídeos na microrregião do Brejo Paraibano.

\section{MATERIAL E MÉTODOS}

O projeto foi aprovado no Comitê de Ética no Uso de Animais da Universidade Federal Rural de Pernambuco com a licença noo $002 / 2012$.

A microrregião do Brejo Paraibano está inserida na mesorregião do Agreste, e é composta por oito municípios: Alagoa Grande, Alagoa Nova, Areia, Bananeiras, Borborema, Matinhas, Pilões e Serraria (IBGE 2012). Para o estudo de prevalência o plano amostral foi dividido em dois estágios. No primeiro estágio, foram selecionadas todas as propriedades com criação de dez ou mais equídeos (unidades primárias de amostragem), visto que, são essas propriedades que realmente fazem parte da cadeia produtiva da equideocultura, totalizando 26 propriedades; no segundo, foi sorteado, de forma aleatória, um número pré-estabelecido de equídeos (unidades secundárias de amostragem). A amostra de cada propriedade foi calculada com o auxílio do programa Win Episcope 2.0. Para compor a amostra do estudo da prevalência foi considerada uma prevalência de 50\%, visto que não há dados sobre a ocorrência desta infecção nesta microrregião. Em cada propriedade também foi considerada uma confiança mínima de 95\% e erro estatístico de 10\%. Desta forma, foram coletadas 257 amostras sanguíneas de equídeos (equinos, asininos e muares) clinicamente saudáveis, de diferentes sexos e finalidade, no período compreendido entre julho e dezembro de 2011.

A escolha das unidades primárias de amostragem foi baseada no cadastro de propriedades rurais com equídeos, da Secretaria de Estado do Desenvolvimento da Agropecuária e da Pesca (SEDAP). A propriedade selecionada que, por motivos vários, não pôde ser visitada, foi substituída por outra, nas proximidades, com as mesmas características de produção. A propriedade selecionada que, no momento da visita, possuía menos que os dez equídeos previstos anteriormente também foi amostrada, e nesse caso foram coletadas amostras de todos os animais.

Apenas um dos oito municípios da microrregião não foi amostrado, pois, segundo o cadastro, não havia propriedades que atendessem ao critério de seleção de pelo menos dez equídeos. Os municípios pesquisados foram: Areia $(n=42 ; 28$ equinos, 1 asinino e 13 muares), Serraria ( $n=13 ; 9$ equinos e 4 muares), Alagoa Grande ( $n=67 ; 54$ equinos, 2 asininos e 11 muares), Bananeiras ( $n=108$; 93 equinos, 03 asininos e 12 muares), Pilões ( $n=3 ; 3$ muares), Borborema ( $n=7 ; 4$ equinos, 1 asinino e 2 muares) e Alagoa Nova ( $n=17 ; 16$ equinos e 1 muar).

Os equídeos eram criados a campo, semi-estabulados ou estabulados. Em relação à raça, os animais testados eram sem raça definida (SRD) (152), Quarto-de-milha (15), mestiços de Quarto-de-milha (74) e Manga-larga (16). Nesta microrregião, os equídeos são utilizados com as finalidades de esporte (vaquejada), reprodução, trabalho ou lazer. As idades dos animais foram agrupadas em três estratos: abaixo de 2,5 anos de idade (animais jovens), entre 2,5 e 11 anos (animais em idade reprodutiva) e acima de 11 anos (animais idosos). Quanto ao sexo 116 eram fêmeas e 141 machos. 
As amostras de sangue foram obtidas por venopunção da jugular, com sistema de colheita a vácuo, em tubos siliconizados com capacidade para $10 \mathrm{~mL}$. As amostras sanguíneas colhidas foram mantidas em temperatura ambiente até a retração do coágulo sanguíneo, em seguida transportadas ao laboratório sob refrigeração, onde foram centrifugadas, durante 10 minutos, a $900 \mathrm{~g}$. 0 soro obtido foi transferido para tubos de polipropileno sendo armazenados em temperatura de freezer a $-20^{\circ} \mathrm{C}$, até o momento da realização dos testes sorológicos.

Para a pesquisa de anticorpos IgG anti-Toxoplasma gondii foi utilizada a técnica de Imunofluorescência Indireta de acordo com Camargo (1974), utilizando ponto de corte 64. A RIFI foi realizada em duas fases, sendo a primeira de caráter qualitativo, triagem (1:64), e a segunda de caráter quantitativo (titulação). Foram utilizados soros controles negativo e positivo com títulos previamente conhecidos. A reação positiva foi caracterizada pela fluorescência intensa total na superfície dos taquizoítos, adotando-se como positivos todos os soros reagentes na diluição 1:64 e negativas as reações que possuíam fluorescência apical ou parcial. A leitura foi realizada em microscópio epifluorescente.

Em cada propriedade amostrada foram aplicados questionários epidemiológicos, elaborados para obter informações sobre o tipo de exploração e as práticas de manejo empregadas, de forma a permitir a realização do estudo de fatores de risco. No total, 21 variáveis foram incluídas na análise. As variáveis foram agrupadas por: a) dados individuais: espécie (equino, asinino e muar), faixa etária (<2,5 anos, 2,5-11 anos e >11 anos) e sexo (macho e fêmea), b) dados do rebanho: área (rural e peri-urbana), tamanho do rebanho $(<10,10-30$ e $>30)$, presença de outras espécies de animais domésticos (gatos e aves), presença de animais silvestres, criação consorciada com outros animais, sistema de criação (a campo, semi-estabulado e estabulado), alimentação (com e sem suplementação) e fornecimento de feno, c) biosseguridade: limpeza e desinfecção, fontes de água (parada, corrente e parada+corrente), acesso de gatos à ração e à fonte de água, aluguel de pasto, tipo de rebanho (aberto e fechado), procedência dos animais (comerciantes, leilão/exposição e ambos) e quarentena.

Foi utilizada a análise estatística descritiva para cálculos das frequências relativa e absoluta dos resultados obtidos no teste sorológico. Para identificar os fatores de risco associados à infecção, foi realizada uma análise univariada das variáveis de interesse através do teste qui-quadrado de Pearson, ou Exato de Fisher, quando necessário. Posteriormente foi realizada uma análise de regressão logística, considerando como variável dependente o exame sorológico (positivo ou negativo). As variáveis independentes ou explanatórias consideradas no modelo foram aquelas que apresentaram significância estatística $<0,20$. Essa probabilidade foi estipulada para que possíveis fatores de risco do evento não fossem excluídos da análise (Hosmer \& Lemeshow 1989). A propriedade foi considerada como foco quando foi detectado pelo menos um animal positivo. O programa SPSS for Windows, versão 18,0 - Statistical Package for the Social Science, foi utilizado para a execução dos cálculos estatísticos.

\section{RESULTADOS}

Dos equídeos examinados, 7,8\% (20/257) foram positivos ao teste sorológico, com títulos variando de 1:64 a 1:256 (Quadro 1).

Dos rebanhos equídeos examinados $46,1 \%(12 / 26)$ tiveram pelo menos um animal soropositivo, sendo considerados como focos. Dos sete municípios pesquisados, cinco $(71,4 \%)$ possuíam animais positivos. As soroprevalências nos municípios amostrados foram: 28,6\% em Borborema
(2/7); 11,8\% em Alagoa Nova (2/17); 10,4\% em Alagoa Grande (7/67); 6,5\% em Bananeiras (7/108); 4,8\% em Areia (2/42); e $0 \%$ em Serraria (0/13) e Pilões (0/3). Em relação às áreas rural e peri-urbana, observou-se que $7,2 \%$ $(16 / 221)$ dos animais procedentes da área rural e 11,1\% (4/36) da peri-urbana foram positivos.

Quadro 1. Frequência de anticorpos anti-Toxoplasma gondii e titulação em equídeos, na microrregião do Brejo Paraibano

\begin{tabular}{lcccccc}
\hline Espécie & No & No & & \multicolumn{3}{c}{ Títulos } \\
& amostras & positivos & $\%$ & $1: 64$ & $1: 128$ & $1: 256$ \\
\hline Equina & 204 & 17 & 8,3 & $4(2,0 \%)$ & $8(3,9 \%)$ & $5(2,4 \%)$ \\
Asinina & 7 & 2 & 28,6 & $1(14,3 \%)$ & $1(14,3 \%)$ & 0 \\
Muar & 46 & 1 & 2,2 & $1(2,2 \%)$ & 0 & 0 \\
Total & 257 & 20 & 7,8 & $6(30 \%)$ & $9(45 \%)$ & $5(25 \%)$
\end{tabular}

Quadro 2. Análise univariada dos fatores de risco (dados individuais e de rebanho) associados à infecção por Toxoplasma gondii em equídeos no Brejo Paraibano

\begin{tabular}{|c|c|c|c|c|c|c|c|}
\hline \multirow[t]{3}{*}{ Variáveis } & \multicolumn{4}{|c|}{ Sorologia } & \multicolumn{2}{|c|}{ Total } & \multirow[t]{3}{*}{ Valor $\mathrm{p}$} \\
\hline & \multicolumn{2}{|c|}{ Positivo } & \multicolumn{2}{|c|}{ Negativo } & \multirow[t]{2}{*}{$\overline{\mathrm{FA}}$} & \multirow[t]{2}{*}{ FR\% } & \\
\hline & FA & FR\% & FA & FR\% & & & \\
\hline \multicolumn{8}{|l|}{ Área } \\
\hline Rural & 16 & 7,2 & 205 & 92,8 & 221 & 100 & 0,301 \\
\hline Peri-urbana & 4 & 11,1 & 32 & 88,9 & 36 & 100 & \\
\hline \multicolumn{8}{|l|}{ Espécie } \\
\hline Equino & 17 & 8,3 & 187 & 91,7 & 204 & 100 & $0,042 *$ \\
\hline Muar & 1 & 2,2 & 45 & 97,8 & 46 & 100 & \\
\hline Asinino & 2 & 28,6 & 5 & 71,4 & 7 & 100 & \\
\hline \multicolumn{8}{|l|}{ Sexo } \\
\hline Macho & 10 & 7,1 & 131 & 92,9 & 141 & 100 & 0,410 \\
\hline Fêmea & 10 & 8,6 & 106 & 91,4 & 116 & 100 & \\
\hline \multicolumn{8}{|l|}{ Idade (anos) } \\
\hline$<2,5$ & 3 & 7,0 & 40 & 93,0 & 43 & 100 & 0,183 \\
\hline Entre 2,5 entre 11 & 16 & 9,8 & 147 & 90,2 & 163 & 100 & \\
\hline Acima de 11 & 1 & 2,0 & 50 & 98,0 & 51 & 100 & \\
\hline \multicolumn{8}{|l|}{ Sistema de criação } \\
\hline A campo & 6 & 6,3 & 90 & 93,8 & 96 & 100 & 0,699 \\
\hline Semi & 14 & 8,8 & 145 & 91,2 & 159 & 100 & \\
\hline Estabulado & - & - & 2 & 100 & 2 & 100 & \\
\hline \multicolumn{8}{|c|}{ Quantidade de equídeos na propriedade } \\
\hline$<10$ & 3 & 4,6 & 62 & 95,4 & 65 & 100 & $0,002^{*}$ \\
\hline Entre 10 e 30 & 10 & 6,1 & 153 & 93,9 & 163 & 100 & \\
\hline$>30$ & 7 & 24,1 & 22 & 75,9 & 29 & 100 & \\
\hline \multicolumn{8}{|l|}{ Criação consorciada } \\
\hline Sim & 18 & 8,3 & 199 & 91,7 & 217 & 100 & 0,368 \\
\hline Não & 2 & 5,0 & 38 & 95,0 & 40 & 100 & \\
\hline \multicolumn{8}{|l|}{ Presença de aves } \\
\hline Sim & 15 & 9,3 & 146 & 90,7 & 161 & 100 & 0,172 \\
\hline Não & 5 & 5,2 & 91 & 94,8 & 96 & 100 & \\
\hline \multicolumn{8}{|l|}{ Presença de Gatos } \\
\hline Sim & 10 & 5,8 & 163 & 94,2 & 173 & 100 & 0,073 \\
\hline Não & 10 & 11,9 & 74 & 88,1 & 84 & 100 & \\
\hline \multicolumn{8}{|c|}{ Presença de Animais Silvestres } \\
\hline Sim & 15 & 7,7 & 180 & 92,3 & 195 & 100 & 0,554 \\
\hline Não & 5 & 8,1 & 57 & 91,9 & 62 & 100 & \\
\hline \multicolumn{8}{|l|}{ Alimentação } \\
\hline Com suplementação & 15 & 7,9 & 174 & 92,1 & 189 & 100 & 0,557 \\
\hline Sem suplementação & 5 & 7,4 & 63 & 92,6 & 68 & 100 & \\
\hline \multicolumn{8}{|l|}{ Feno } \\
\hline Sim & 1 & 7,7 & 12 & 92,3 & 13 & 100 & 0,660 \\
\hline Não & 19 & 7,8 & 225 & 92,2 & 244 & 100 & \\
\hline
\end{tabular}

*Associação significativa ao nível 5\%. 
Quanto à idade observou-se que todos os animais positivos tinham idade variando entre 8 meses e 17 anos. Analisando os resultados por estrato etário, constatou-se que $7,0 \%$ de soropositividade foi observada nos equídeos com menos de 2,5 anos, 9,8\% entre 2,5 e 11 anos, e 2,0\% acima de 11 anos. Quanto ao sexo, dez $(8,6 \%)$ fêmeas e dez $(7,1 \%)$ machos foram soropositivos.

Ao analisar os fatores de risco na análise univariada observou-se que as variáveis espécie $(\mathrm{p}=0,042)$, número de equídeos na propriedade $(\mathrm{p}=0,002)$, fonte de água $(\mathrm{p}=0,009)$ e quarentena $(\mathrm{p}=0,037)$ apresentaram associação significativa (Quadros 2 e 3). Na regressão logística das variáveis observou-se que a fonte de água foi um fator de risco, pois naquelas propriedades que forneciam água corrente para os animais o risco de infecção foi 4,4 vezes maior do que naquelas propriedades que forneciam água parada (OR 4,4; I.C. 1,0-19,0) (Quadro 4).

Quadro 3. Análise univariada dos fatores de risco (biosseguridade) associados à infecção por T. gondii em equídeos no Brejo Paraibano

\begin{tabular}{|c|c|c|c|c|c|c|c|}
\hline \multirow[t]{3}{*}{ Variáveis } & \multicolumn{4}{|c|}{ Sorologia } & \multicolumn{2}{|c|}{ Total } & \multirow[t]{3}{*}{ Valor $\mathrm{p}$} \\
\hline & \multicolumn{2}{|c|}{ Positivo } & \multicolumn{2}{|c|}{ Negativo } & \multirow[t]{2}{*}{ FA } & \multirow[t]{2}{*}{ FR\% } & \\
\hline & FA & FR\% & FA & FR\% & & & \\
\hline \multicolumn{8}{|l|}{ Fonte de água } \\
\hline Parada & 4 & 4,3 & 90 & 95,7 & 94 & 100 & $0,009^{a}$ \\
\hline Corrente & 13 & 14,9 & 74 & 85,1 & 87 & 100 & \\
\hline Parada + corrente & 3 & 3,9 & 73 & 96,1 & 76 & 100 & \\
\hline \multicolumn{8}{|l|}{ Limpeza $^{b}$} \\
\hline Sim & 18 & 7,9 & 211 & 92,1 & 229 & 100 & 0,633 \\
\hline Não & 1 & 8,3 & 11 & 91,7 & 12 & 100 & \\
\hline \multicolumn{8}{|c|}{ Uso de desinfetantes ${ }^{b}$} \\
\hline Sim & 1 & 4,8 & 20 & 95,2 & 21 & 100 & 0,568 \\
\hline Não & 17 & 8,2 & 191 & 91,8 & 208 & 100 & \\
\hline \multicolumn{8}{|c|}{ Gatos têm acesso à ração ${ }^{\text {b }}$} \\
\hline Sim & - & - & 13 & 100 & 13 & 100 & 0,325 \\
\hline Não & 19 & 8,5 & 204 & 91,5 & 223 & 100 & \\
\hline \multicolumn{8}{|c|}{ Gatos têm acesso à fonte de água } \\
\hline Sim & 5 & 6,8 & 68 & 93,2 & 73 & 100 & 0,475 \\
\hline Não & 15 & 8,2 & 169 & 91,8 & 184 & 100 & \\
\hline \multicolumn{8}{|l|}{ Aluguel de pasto } \\
\hline Sim & 2 & 9,1 & 20 & 90,9 & 22 & 100 & 0,528 \\
\hline Não & 18 & 7,7 & 217 & 92,3 & 235 & 100 & \\
\hline \multicolumn{8}{|l|}{ Tipo do rebanho } \\
\hline Aberto & 19 & 8,3 & 210 & 91,7 & 229 & 100 & 0,331 \\
\hline Fechado & 1 & 3,6 & 27 & 96,4 & 28 & 100 & \\
\hline \multicolumn{8}{|c|}{ Procedência dos animais ${ }^{b}$} \\
\hline Comerciante & 16 & 8,0 & 183 & 92,0 & 199 & 100 & 0,864 \\
\hline Leilão/exposição & 2 & 11,8 & 15 & 88,2 & 17 & 100 & \\
\hline Ambos & 1 & 7,7 & 12 & 92,3 & 13 & 100 & \\
\hline \multicolumn{8}{|l|}{ Realiza quarentena } \\
\hline Sim & 12 & 12,4 & 85 & 87,6 & 97 & 100 & $0,037^{\mathrm{a}}$ \\
\hline Não & 8 & 5,0 & 152 & 95,0 & 160 & 100 & \\
\hline
\end{tabular}

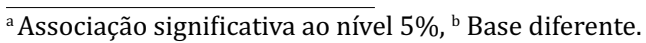

Quadro 4. Regressão logística dos fatores de risco associados à infecção por Toxoplasma gondii em equídeos no Brejo Paraibano

\begin{tabular}{|c|c|c|c|c|}
\hline Variáveis & Valor de $\mathrm{p} \mathrm{OR}^{\mathrm{b}}$ & IC $95 \%^{c}$ & Coeficiente & S.E. ${ }^{\mathrm{d}}$ \\
\hline \multicolumn{5}{|l|}{ Fonte } \\
\hline Cor & 4,4 & $1.0 \quad 19.0$ & 1. & 0,747 \\
\hline Corrente + Parada/ Parada & 0,944 & $0,2 \quad 5,2$ & 0,057 & 0,820 \\
\hline
\end{tabular}

${ }^{\text {a }}$ Associação significativa ao nível $5 \%,{ }^{b}$ Odds ratio (Razão de chance), ${ }^{c}$ Intervalo de confiança de $95 \%$ d Erro padrão da estimativa.

\section{DISCUSSÃO}

Este é o primeiro estudo epidemiológico na microrregião do Brejo Paraibano a analisar a infecção por Toxoplasma gondii em equídeos. Nesta microrregião, 7,8\% foram positivos na RIFI. Estudos realizados em diversas partes do mundo revelaram prevalências que variam de $0,4 \%$ a $71,2 \%$ (Dubey et al. 2003, Akca et al. 2004, Jakubek, Lundén \& Uggla 2006, Ghazy, Shaapan \& Abdel-Rahman 2007, Göz et al. 2007, Güçlü et al. 2007, Bártová et al. 2010, Hajialilo et al. 2010, Karatepe et al. 2010, Kouam et al. 2010, Alanazi \& Alyousif 2011, Boughattas et al. 2011, Dangoudoubiyam et al. 2011, Shaapan et al. 2012, García-Bocanegra et al. 2012). No Brasil, resultados próximos ao do presente trabalho foram obtidos por Langoni et al. (2007) e Gazêta et al. (1997), que encontraram $138(7,0 \%)$ amostras positivas no MAT e $4,42 \%$ na RIFI, respectivamente.

A diferença de prevalência entre os estudos realizados pode ser devido à amostragem realizada, às condições ambientais, técnicas sorológicas e interpretação dos resultados quanto ao ponto de corte utilizado. Outros fatores também podem influenciar nos resultados, tais como: tipo de criação (extensiva, semi-intensiva e intensiva), tipo de alimentação (com ou sem suplementação), fonte de água, época em que as amostras foram coletadas, e presença de felídeos.

É difícil comparar precisamente os resultados desta pesquisa com estudos publicados anteriormente, porque diferentes planos amostrais, métodos de diagnóstico e pontos de corte foram utilizados. Analisando o método de diagnóstico para infecção por T. gondii em equídeos constata-se que o teste ouro permanece desconhecido, uma vez que existe um menor número de estudos em equinos quando se compara com outras espécies domésticas (Camossi et al. 2010). A sensibilidade e especificidade dos testes sorológicos em equinos são pouco conhecidas (Shaapan et al. 2012). Na literatura consultada os estudos de inquérito epidemiológicos em outras partes do mundo geralmente utilizam o MAT como método de diagnóstico (Dubey et al. 1999a, 1999b, Shaapan et al. 2012), enquanto no Brasil, a RIFI é mais utilizada (Laranjeira et al. 1985, Gazêta et al. 1997, Vidotto et al. 1997, Garcia et al. 1999, Naves et al. 2005, Locatelli-Dittrich et al. 2006, Coiro et al. 2012). A utilização da RIFI com ponto de corte de 1:64 diminui o número de reações falso-positivas que podem ocorrer em baixas diluições e tem maior concordância com outros testes como o MAT. Segundo Coiro et al. (2012), para baixas diluições de soro, reações inespecíficas podem ocorrer com outros parasitos, tais como Hammondia hammondi.

Acredita-se que a baixa prevalência encontrada nesse estudo esteja relacionada à resistência dos equídeos, hipótese reforçada por Mendonça et al. (2001), que atribuem a baixa prevalência encontrada à resistência natural dos equídeos à infecção por T. gondii.

A maior titulação (256) só foi encontrada na espécie equina. Este fato pode ser justificado pela maior parte dos equinos terem acesso à água corrente, que foi considerada um fator de risco importante, provavelmente aumentando a exposição desses animais a oocistos e consequentemente o nível de anticorpos. 
Ao analisar a prevalência por espécie, observou-se que $8,3 \%(17 / 204)$ dos equinos, $2,2 \%(1 / 46)$ dos muares e $28,6 \%(2 / 7)$ dos asininos foram positivos. García-Bocanegra et al. (2012) obtiveram os seguintes valores de prevalência: $10,8 \%$ em equinos, $15,0 \%$ em muares e $25,6 \%$ em asininos. A maior prevalência em asininos pode ser justificada pelo fato de esses animais possuírem menor valor zootécnico, e consequentemente os proprietários não despendem muitos cuidados sanitários com esses animais. El-Ghaysh (1998), trabalhando apenas com asininos, encontrou uma alta prevalência em comparação a prevalências de cavalos obtidas em outros estudos, e indica que esse fato pode ser devido ao contato entre asininos e gatos em torno de habitações. García-Bocanegra et al. (2012) atribuem a alta prevalência em asininos a eles serem mantidos mais livres com maior acesso a parasitos. Animais que não são criados livremente têm contato limitado com fezes de felídeos (Kouam et al. 2010). Neste sentido, constatou-se uma menor prevalência em animais mantidos estabulados $(0,0 \%)$ versus aqueles mantidos semi-estabulados $(8,8 \%)$ ou a campo $(6,3 \%)$, embora as diferenças não tenham sido estatisticamente significativas.

O elevado número de focos, $46,1 \%$, possibilita assinalar a microrregião do Brejo Paraibano como enzoótica para infecção por T. gondii. Especificamente, o município de Borborema apresentou a maior prevalência, que pode ser justificada pela fonte de água exclusivamente corrente fornecida aos animais. Não foi observada neste estudo diferença estatisticamente significativa no que se refere às variáveis idade e sexo, o que confirma os resultados verificados por Mendonça et al. (2001) e Camossi et al. (2010). Isso confirma a hipótese de que não existe diferença de susceptibilidade com relação a essas duas variáveis. Entretanto, observou-se uma maior prevalência nos animais com idade entre 2,5 e 11 anos, o que está de acordo com Boughattas et al. (2011), que relatam que a soroprevalência em equinos adultos foi significativamente maior do que aquela de equinos jovens, fornecendo evidências adicionais para o aumento do risco de infecção por T. gondii com o aumento de idade através da exposição cumulativa ao longo da vida a oocistos infectantes a partir do ambiente.

Gazêta et al. (1997), no Rio de Janeiro, encontraram maior prevalência de animais positivos manejados em ambiente urbano comparada com a de animais positivos em áreas rurais, o que concorda com os resultados apresentados, considerando áreas rurais e peri-urbanas. Isto pode ser justificado pela maior concentração de gatos em áreas urbanas e peri-urbanas. El-Ghaysh (1998) indica que maiores prevalências podem ser devido ao contato entre os animais e gatos em torno de habitações.

Nesse estudo não foi observada associação significativa entre presença de gatos e de animais silvestres e positividade para infecção por T. gondii em equídeos. García-Bocanegra et al. (2012) também não encontraram diferenças com relação à presença de gatos. Apesar de não ter havido associação significativa, os proprietários devem manter felídeos longe das instalações, pastagens e fontes de água, pois estas são as espécies de maior importância epidemiológica no ciclo de vida do parasito, porque eles são os hospedei- ros que podem excretar o oocisto, a fase ambientalmente resistente (Dubey \& Jones 2008). Acredita-se que, uma parte dos animais positivos também pode ter se infectado em outra propriedade, pois uma maior prevalência foi encontrada em rebanhos abertos, apesar de não haver associação significativa. Desta forma, sugere-se que ao introduzir novos animais em uma propriedade, devem-se adotar as devidas medidas sanitárias para que se evite a introdução de agentes infecciosos.

A fonte de água exclusivamente corrente foi considerada um fator de risco importante; logo, os animais podem ter se infectado pela ingestão de água que foi contaminada a montante do ponto do curso de água que passava na propriedade. Quinze propriedades forneciam água corrente aos animais, das quais foram encontrados animais positivos em oito (53,3\%). Aramini et al. (1999) observaram fezes de puma (Felis concolor) ao lado de córregos que, eventualmente, drenavam para reservatórios de água associados a um surto de toxoplasmose em humanos.

Propriedades com mais de 30 equídeos apresentaram maior prevalência de animais positivos. Em rebanhos maiores não há diferenças individuais quanto à susceptibilidade à infecção, mas algumas características desses rebanhos podem facilitar a transmissão de certos agentes como o $T$. gondii: maior frequência de reposição de animais e maior número de problemas relacionados ao controle sanitário. Portanto, em propriedades com maior número de animais, os cuidados sanitários devem ser reforçados.

\section{CONCLUSÃO}

A soroprevalência geral de Toxoplsma gondii em equídeos na microrregião do Brejo Paraibano foi relativamente baixa, entretanto o número de focos foi elevado. Isto significa que os animais estão (ou estiveram) em contato com este parasito e que seus tecidos podem abrigar cistos teciduais e assim representar uma fonte de infecção para outras espécies, incluindo os hospedeiros definitivos. Os proprietários devem fornecer aos seus animais uma água de boa qualidade, para diminuir os riscos de infecção, bem como se deve evitar acesso de gatos a fontes de água. Considerando o valor zootécnico de alguns animais, é importante avaliar a importância clínica da toxoplasmose em equídeos e considerar os aspectos relacionados à saúde pública.

\section{REFERÊNCIAS}

Akca A., Babur C., Arslan M.O., Gicik Y., Kara M. \& Kilic S. 2004. Prevalence of antibodies to Toxoplasma gondii in horses in the province of Kars, Turkey. Vet Med. 49:9-13.

Alanazi A.D. \& Alyousif M.S. 2011. Prevalence of Antibodies to Toxoplasma gondii in Horses in Riyadh Province, Saudi Arabia. J. Parasitol. 97:943945.

Aramini J.J., Stephen C., Dubey J.P., Engelstoft C., Schwantje H. \& Ribble C.S. 1999. Potential contamination of drinking water with Toxoplasma gondii oocysts. Epidemiol. infect. 122:305-315.

Balkaya I., Babur C., Celebi B. \& Utuk A.E. 2011. Seroprevalence of toxoplasmosis in donkeys in Eastern Turkey. Israel J. Vet. Med. 66:39-42.

Bártová E., Sedlák K., Syrová M. \& Literák I. 2010. Neospora spp. and Toxoplasma gondii antibodies in horses in the Czech Republic. Parasitol. Res. 107:783-785. 
Beech J. \& Dodd D.C. 1974. Toxoplasma-like Encephalomyelitis in the Horse. Vet. Pathol. 11: 87-96.

Boughattas S., Bergaoui R., Essid R., Aoun K. \& Bouratbine A. 2011. Seroprevalence of Toxoplasma gondii infection among horses in Tunisia. Parasit. Vectors 4:218.

Camargo M.E. 1974. Introdução às técnicas de imunofluorescência. Rev. Bras. Patol. Clin. 10:143-169.

Camossi L.G., Silva A.V. \& Langoni H. 2010. Inquérito sorológico para toxoplasmose em equinos na região de Botucatu-SP. Arq. Bras. Med. Vet. Zootec. 62:484-488.

Coiro C.J., Langoni H. \& Silva R.C. 2012. Epidemiological Aspects in the Leptospira spp. and Toxoplasma gondii Infection in Horses from Botucatu, São Paulo, Brazil. J. Equine Vet. Sci. 1:4. (Em publicação)

Dangoudoubiyam S., Oliveira J.B., Víquez C., Gómez-García A., González O., Romero J.J., Kwok O.C.H., Dubey J.P. \& Howe D.K. 2011. Detection of antibodies against Sarcocystis neurona, Neospora spp., and Toxoplasma gondii in horses from Costa Rica. J. Parasitol. 97:522-524.

Dubey J.P. 2004. Toxoplasmosis, a waterborne zoonosis. Vet. Parasitol. 126:57-72.

Dubey J.P. \& Jones J.L. 2008. Toxoplasma gondii infection in humans and animals in the United States. Int. J. Parasitol. 38:1257-1278.

Dubey J.P., Mitchell S.M., Morrow J.K., Rhyan J.C., Stewart L.M., Granstrom D.E., Romand S., Thulliez P., Saville W.J. \& Lindsay D.S. 2003. Prevalence of antibodies to Neospora caninum, Sarcocystis neurona, and Toxoplasma gondii in wild horses from Central Wyoming. J. Parasitol. 89:716-720.

Dubey J.P., Thulliez P., Romand S., Kwok O.C.H., Shen S.K. \& Gamble H.R. 1999a. Serologic prevalence of Toxoplasma gondii in horses slaughtered for food in North America. Vet. Parasitol. 86:235-238.

Dubey J.P., Venturini M.C., Venturini L., McKinney J. \& Pecoraro M. 1999b. Prevalence of antibodies to Sarcocystis neurona, Toxoplasma gondii and Neospora caninum in horses from Argentina. Vet. Parasitol. 86:59-62.

El-Ghaysh A. 1998. Seroprevalence of Toxoplasma gondii in Egyptian donkeys using ELISA. Vet. Parasitol. 80:71-73.

Fialho C.G., Teixeira M.C. \& Araújo F.A.P. 2009. Toxoplasmose animal no Brasil. Acta sci. vet. 37:1-23.

Fraser C.M. 1996. Manual Merck de Veterinária: um manual de diagnóstico, tratamento, prevenção e controle de doenças para o veterinário. 7 . ed. Roca, São Paulo. p.565.

García-Bocanegra I., Cabezón O., Arenas-Montes A., Carbonero A., Dubey J.P., Perea A. \& Almería S. 2012. Seroprevalence of Toxoplasma gondii in equids from Southern Spain. Parasitol Int. doi:10.1016/j.parint.2012.02.003. (no prelo).

Garcia J.L., Navarro I.T., Ogawa L. \& Oliveira R.C. 1999. Soroprevalência do Toxoplasma gondii, em suínos, bovinos, ovinos e eqüinos, e sua correlação com humanos, felinos e caninos, oriundos de propriedades rurais do norte do Paraná - Brasil. Cienc. Rural. 29:91-97.

Gazêta G.S., Dutra A.E.A., Norberg A.N., Serra-freire N.M., Souza W.J.S., Amorim M. \& Lopes L.M.S. 1997. Freqüência de anticorpos anti-Toxoplasma gondii em soros de eqüinos no estado do Rio de Janeiro, Brasil. Rev. Bras. Parasitol. Vet. 6:87-91.

Ghazy A.A., Shaapan R.M. \& Abdel-Rahman E.H. 2007. Comparative serological diagnosis of toxoplasmosis in horses using locally isolated Toxoplasma gondii. Vet. Parasitol. 145:31-36.
Göz Y., Babür C., Aydin A. \& Kiliç S. 2007. Seroprevalence of toxoplasmosis, brucellosis and listeriosis in horses in Hakkari, eastern region of Turkey. Rev Med Vet. 158:534-539.

Güçlü Z., Karaer Z., Babür C. \& Kiliç S. 2007. Investigation of Toxoplasma gondii antibodies in sport horses bred in Ankara province. Turkiye Parazitol. Derg. 31:264-267.

Gupta G.D., Lakritz J., Kim J., Kim D., Kim J. \& Marsh A.E. 2002. Seroprevalence of Neospora, Toxoplasma gondii and Sarcocystis neurona antibodies in horses from Jeju island, South Korea. Vet. Parasitol. 106:193-201.

Hajialilo E., Ziaali N., Harandi M.F., Saraei M. \& Hajialilo M. 2010. Prevalence of anti-Toxoplasma gondii antibodies in sport horses from Qazvin, Iran. Trop. Anim. Health Prod. 42:1321-1322.

Hosmer D.W. \& Lemeshow S. 1989. Applied Logistic Regression. John Wiley and Sons, New York. 241p.

Instituto Brasileiro de Geografia e Estatística. Rio de Janeiro. Disponível em <http://www.ibge.gov.br/estadosat/perfil.php?sigla=pb> Acesso em 4 mai. 2012.

Jakubek E.B., Lundén A. \& Uggla A. 2006. Seroprevalences of Toxoplasma gondii and Neospora sp. infections in Swedish horses. Vet. Parasitol. 138:194-199.

Karatepe B., Babur C., Karatepe M. \& Kilıc S. 2010. Seroprevalence of toxoplasmosis in horses in Nigde Province of Turkey. Trop. Anim. Health Prod. 42:385-389.

Kouam M.K., Diakou A., Kanzoura V., Papadopoulos E., Gajadhar A.A. \& Theodoropoulos G. 2010. A seroepidemiological study of exposure to Toxoplasma, Leishmania, Echinococcus and Trichinella in equids in Greece and analysis of risk factors. Vet. Parasitol. 170:170-175.

Langoni H., Silva A.V., Pezerico S.B. \& Lima V.Y. 2007. Utilization of modified agglutination test and indirect immunofluorescent antibody test for the detection of Toxoplasma gondii antibodies in naturally exposed horses. Braz. J. Vet. Res. Anim. Sci. 44:27-32.

Laranjeira N.L., Ishizuka M.M. \& Hyakutake S. 1985. Prevalência da toxoplasmose equina avaliada pela técnica de imunofluorescência indireta, Mato Grosso do Sul, Brasil. Bol. Oficina Sanit. Panam. 99:158-162.

Locatelli-Dittrich R., Dittrich J.R., Richartz R.R.T.B., Joineau M.E.G., Antunes J., Pinckney R.D., Deconto I., Hoffmann D.C.S. \& Thomaz-Soccol V. 2006. Investigation of Neospora sp. and Toxoplasma gondii antibodies in mares and in precolostral foals from Parana State, Southern Brazil. Vet. Parasitol. 135:215-221.

Mendonça A.O., Cerqueira E.J.L., Araujo W.N., Moraes-Silva E., Shimabukuro F.H., Sarkis D.T., Sherlock I. \& Langoni H. 2001. Inquérito sorológico para toxoplasmose em equídeos procedentes de duas regiões do Estado da Bahia, Brasil. Semina, Ciênc. Agrar. 22:115-118.

Naves C.S., Ferreira F.A., Carvalho F.S. \& Costa G.H. 2005. Soroprevalência da toxoplasmose em equinos da raça mangalarga marchador no município de Uberlândia, Minas Gerais. Vet. Notícias, Uberlândia, 11:45-52.

Shaapan R.M., Abo-ElMaaty A.M., Abd El-Razik K.A. \& Abd El-Hafez S.M. 2012. PCR and serological assays for detection of Toxoplasma gondii infection in sport horses in Cairo, Egypt. Asian J. Anim. Vet. Adv. 7:158165.

Vidotto O., Kano F.S., Freire R.L., Mitsuka R., Ogawa L., Bonesi G., Navarro I.T. \& Franciscon F.S.G. 1997. Ocorrência de anticorpos anti-Toxoplasma gondii em eqüinos procedentes de quatro estados (SP, PR, MS e MT) abatidos em Apucarana, PR. Semina, Ciênc. Agrar. 18:9:13. 